\title{
SIN-E-STRES: An adjunct Internet-based intervention for the treatment of patients with posttraumatic stress disorder in Chile
}

\author{
SIN-E-STRES: una intervención complementaria basada en \\ Internet para el tratamiento de pacientes con trastorno de estrés \\ postraumático en Chile
}

\author{
Álvaro E. Carrasco 1 ORCID , Markus Moessner ${ }^{2} \underline{\text { ORCID }}$, Carmen G. Carbonell ${ }^{3} \underline{\text { ORCID, }}$ \\ Catalina Rodríguez C. ${ }^{4} \underline{\text { ORCID }}$, Natalia Martini ${ }^{5}$, Janet C. Pérez ${ }^{6} \underline{\text { ORCID }}$, Pablo Garrido ${ }^{7}$, \\ Fikret Özer ${ }^{8} \underline{\text { ORCID }}$, Mariane Krause $\stackrel{\text { ORCID }}{\text {, Stephanie Bauer }}{ }^{10} \underline{\text { ORCID }}$,
}

\author{
${ }^{16}$ Millennium Institute for Research on Depression and Personality, Chile. \\ ${ }^{2810}$ Center for Psychotherapy Research, University Hospital, Heidelberg, Germany. \\ ${ }^{35}$ Outpatient Mental Health Unit, Hospital del Trabajador, Asociación Chilena de Seguridad. \\ ${ }^{4}$ Occupational Therapy Unit, Hospital del Trabajador, Asociación Chilena de Seguridad. \\ ${ }^{7}$ School of Psychology, University of Valparaíso, Chile Chile. \\ ${ }^{9}$ Department of Psychology, Pontificia Universidad Católica de Chile.
}

Fecha correspondencia:

Recibido: noviembre 13 de 2019.

Aceptado: julio 23 de 2020.

Forma de citar:

Carrasco, A.E., Moessner, M.,

Carbonell, C. G., Rodríguez, C., Martini,

N., Pérez, J.C., Garrido, P., Özer, F.,

Krause, M., \& Bauer, S. (2020). Sin-

E-Stres: an Adjunct Internet-Based Intervention for the Treatment of

Patients with Posttraumatic Stress

Disorder in Chile. Rev. CES Psico,

13(3), 239-258.

\section{Open access}

(c) Copyright

Licencia creative commons

Ética de publicaciones

Comparte

\section{Abstract}

Introduction: SIN-E-STRES is an adjunct Internet-based intervention for patients with posttraumatic stress disorder (PTSD). Patients interact with the program via a weekly monitoring email and by visiting a website that provides access to psychoeducational information and distance counseling. Aim: to evaluate the acceptability and feasibility of SIN-E-STRES. Methods: forty-five adult PTSD patients were registered to use SIN-E-STRES for three months. This study explores feasibility in terms of patients' interest in joining the program, reported connectivity and use of the website components, and adherence to monitoring. Acceptability is evaluated through the satisfaction expressed by the participants, their opinions regarding the usefulness of the program, and their evaluation of its positive and negative aspects. Results: most of the patients invited to the program were interested in using SIN-E-STRES, and $73 \%$ of the registered patients completed at least one of the monitoring assessments and most of them interacted with the website. The overall monitoring response rate was $35 \%$. Most patients stated that the feedback messages helped them remember themes covered in therapy, they also valued the psychoeducational resources on the website. Conclusions: The program may be especially useful for patients who are frequent Internet and email users. The intervention can be enhanced by improving the monitoring and feedback components as well as by adding complementary psychoeducational information. More research about adherence and dropout of PTSD interventions is necessary. The alignment and coherence of SIN-E-STRES with the main treatment contributes to reinforcing treatment indications and consequently may promote treatment adherence and recovery. 
Revisión por pares

Gestión por Open Journal

System

DOI: http://dx.doi. org/10.21615/cesp.13.3.14 ISSN: 2011-3080

* Author Note. This research was supported by the Fund for Innovation and Competitiveness (FIC) of the Chilean Ministry of Economy, Development and Tourism, through the Millennium Scientific Initiative, Grant N. IS130005.

Sobre los autores:

1. Doctor in Psychology. Clinical psychologist in private practice, Ashiya, Japan.

2. Doctor in Psychology. Researcher at the Center for Psychotherapy Research, University Hospital, Heidelberg, Germany.

3. Psychologist. Clinical coordinator at the Outpatient Mental Health Unit, Hospital del Trabajador, Asociación Chilena de Seguridad.

4. Occupational therapist, Bachelor of Occupational Science. Occupational Therapy Unit, Hospital del Trabajador, Asociación Chilena de Seguridad.

\section{Master in Clinical} Psychology. Outpatient Mental Health Unit, Hospital del Trabajador, Asociación Chilena de Seguridad.

6. Doctor in Psychology. Researcher at the Millennium Institute for Research on Depression and Personality, Chile.
Keywords: Posttraumatic Stress Disorder, PTSD, E-Mental Health, Telehealth, Adjunct Treatment, Internet, Internet-based Interventions.

\section{Resumen}

Introducción: SIN-E-STRES es una intervención complementaria basada en Internet para pacientes con trastorno de estrés postraumático (TEPT). Los pacientes interactúan con el programa mediante un correo electrónico de monitoreo semanal y visitando un sitio web que brinda acceso a información psicoeducativa y asesoramiento a distancia. Objetivo: evaluar la aceptabilidad y viabilidad de SIN-E-STRES. Método: cuarenta y cinco pacientes adultos con TEPT se registraron para usar SIN-E-STRES durante tres meses. Este estudio explora la viabilidad en términos del interés de los pacientes en unirse al programa, sus reportes de conectividad y uso de los componentes del sitio web, y la adherencia al monitoreo. La aceptabilidad se evalúa a través de la satisfacción expresada por los participantes, sus opiniones sobre la utilidad del programa y su evaluación de aspectos positivos y negativos. Resultados: la mayoría de los pacientes invitados al programa estaban interesados en usar SIN-E-STRES, y 73\% de los pacientes registrados completaron al menos una de las evaluaciones de monitoreo y la mayoría de ellos interactuaron con el sitio web. La tasa general de respuesta al monitoreo fue del 35\%. La mayoría de los pacientes declararon que los mensajes de retroalimentación les ayudaron a recordar temas vistos en la terapia, también valoraron los recursos psicoeducativos en el sitio web. Conclusiones: El programa puede ser especialmente útil para pacientes que son usuarios frecuentes de Internet y correo electrónico. La intervención se puede mejorar refinando los componentes de monitoreo y retroalimentación, así como al agregar información psicoeducativa complementaria. Se necesita más investigación sobre la adherencia y el abandono en intervenciones para el TEPT. La alineación y la coherencia de SIN-E-STRES con el tratamiento principal contribuye a reforzar las indicaciones del tratamiento y, en consecuencia, puede promover la adherencia al tratamiento y la recuperación.

Palabras clave: Trastorno de Estrés Postraumático, TEPT, E-Salud Mental, Telesalud, Tratamiento complementario, Internet, Intervenciones basadas en Internet.

\section{Introduction}

Posttraumatic stress disorder (PTSD) is a psychological condition that can present after a traumatic experience. Main symptoms include intrusive memories, hyperarousal, avoidance, and negative changes in thinking and mood (American Psychiatric Association [APA], 2013). For PTSD to be diagnosed, these symptoms must persist for more than one month. PTSD leads to poor quality of life and to increased use of health and other social services (Atwoli, Stein, Koenen, \& McLaughlin, 2015).

International epidemiological studies have found that $40 \%$ to $90 \%$ of the population report having experienced a traumatic episode (Litz, Gray, Bryant, \& Adler, 2002). In Chile, an epidemiological study that used a single open-ended question about traumatic events found that $40 \%$ of the sample reported some type of trauma, while lifetime prevalence of PTSD reaching 4.4\% (Pérez et al., 2009). Consistent with international findings, that study also reported a higher prevalence of PTSD for women (6.2\%) than for men (2.5\%), and a high comorbidity with other psychological disorders such as depression and substance abuse (Pérez et al., 2009). In 2010, three months after a magnitude 8.8 earthquake in Chile, a PTSD prevalence of $11 \%$ was found in a sample of 24,982 individuals, who lived in areas that had been affected by the earthquake; specific prevalence for women (13\%) and men (6\%) were reported (Abeldaño, Fernández, Estario, Enders, \& López de Neira, 2014). 
7. Master in Occupational Psychology. Associate professor, Universidad de Valparaíso (Chile).

8. Center for Psychotherapy Research, University Hospital, Heidelberg, Germany.

9. Doctor in Psychology. Professor, Department of Psychology, Pontificia Universidad Católica de Chile.

10. Doctor in Psychology. Researcher at the Center for Psychotherapy Research, University Hospital, Heidelberg, Germany. chotherapy Research, University Hospital, Heidelberg, Germany.
Pharmacotherapy and psychotherapy are standard treatments for PTSD (Vermetten \& Lanius, 2012). Evidence suggests that trauma-focused cognitive-behavioral therapy is an optimal psychological treatment for this disorder (APA, 2017). Narrative exposure psychotherapy, brief eclectic psychotherapy, and treatments that involve the use of virtual reality have also been shown to be effective for treating PTSD (APA, 2017; Bisson, Roberts, Andrew, Cooper, \& Lewis, 2013; Draper \& Ghiglieri, 2011). In addition, Internet-based interventions have shown promising results (Draper \& Ghiglieri, 2011; Lewis, Roberts, Simon, Bethell, \& Bisson, 2019; Wang, Wang, \& Maercke, 2013).

Internet-based interventions have the potential to add beneficial options to mental healthcare and may address challenges associated with the provision of conventional treatment (World Health Organization, 2010). These opportunities are particularly relevant for a country like Chile due to its long territory and its centralized and limited provision of mental healthcare (Castro, Larraín, Fritsch, \& Rojas, 2012; Errázuriz, Valdés, Vohringer, \& Calvo, 2015). It is also advantageous that $72 \%$ of the households have Internet access and there is a growing connectivity rate (Subsecretaria de Telecomunicaciones [SUBTEL], 2016).

The web-based program SIN-E-STRES (WITHOUT-E-STRESS) is a support and monitoring system for the treatment of PTSD. It is based on a model already implemented for other psychological disorders (Bauer, Wolf, Haug, \& Kordy, 2011; Kordy et al., 2016). SIN-E-STRES was developed as an adjunct intervention for patients undergoing treatment at the Hospital del Trabajador (Workers' Hospital, WH) in Santiago, Chile. There is a comprehensive PTSD treatment program that has been in place at the WH for several years; however, the service is under constant pressure to provide timely and sufficient mental health support. In addition, clinicians at the WH report patient resistance to treatment indications. This resistance has been attributed to patients' efforts to avoid the anxiety-provoking exposure required to ameliorate PTSD in the long term (Gray et al., 2004).

To the best of the authors' knowledge, there are no Internet-based programs for PTSD in Chile or Latin America; therefore, the development of such a program could be a helpful and innovative contribution to the treatment of PTSD in this region. Even though international experience shows promising results, it is important to evaluate the applicability of Internet-based PTSD interventions in the Latin American cultural context, while also taking into account the access to and use of technology in this region.

The aim of this study was to evaluate the acceptability and feasibility of SIN-E-STRES as an adjunct intervention to the standard treatment offered to patients with PTSD. Depending on the results of this exploration, further development of interventions and more in-depth research may be justified.

\section{Characteristics and results of PTSD Internet-based interventions}

Most Internet-based interventions for PTSD follow the cognitive-behavioral model (Amstadter, Broman-Fulks, Zinzow, Ruggiero, \& Cercone, 2009; Benight, Ruzek, \& Waldrep, 2008; Bolton \& Dorstyn, 2015; Kuester, Niemeyer, \& Knaevelsrud, 2016; Sloan, Gallagher, Feinstein, Lee, \& Pruneaue, 2011). These Internet-based interventions often include the following elements: psychoeducation, goal setting, exposure exercises, structured writing assignments, self-confrontation, and cognitive restructuring exercises (Amstadter et al., 2009; Hirai \& Clum, 2005; Lange et al., 2003). In addition, some of these programs integrate adaptive coping strategies, stress management training, self-monitoring techniques, self-efficacy beliefs enhancement methods, and social skills training (Kuester et al., 2016). Internet-based programs relying on emotional disclosure theories using expressive writing approaches have also been implemented (Kuester et al., 2016). Some of these 
In general, the literature shows that much remains to be known regarding which elements of Internet-based Posttraumatic Stress Disorder (PTSD) interventions are more beneficial for patients, what types of patients benefit the most, and how and when therapist contact can contribute to treatment gains (Amstadter et al., 2009; Bolton \& Dorstyn, 2015; Kuester et al., 2016; Sloan et al., 2011). interventions are self-guided while others include varied levels of remote support from therapists. These treatments have been defined as low intensity interventions because specialist therapist time is reduced or used in a cost-effective manner (Richards et al., 2014).

Meta-analyses have consistently shown the effectiveness of Internet-based programs for the treatment of PTSD (Bolton \& Dorstyn, 2015; Kuester at al., 2016; Sloan et al., 2011). Moderate to large effect sizes have been found for PTSD symptom severity compared to passive control conditions (Kuester et al., 2016; Sloan et al., 2011). Nonetheless, researchers agree that it is necessary to conduct more rigorous efficacy studies involving a comparison with an active control and follow-up studies to evaluate the maintenance of intervention results (Bolton \& Dorstyn, 2015; Kuester et al., 2016; Sloan et al., 2011).

Good levels of satisfaction with Internet-based programs and average dropout rates similar to those observed for face-to-face evidence-based PTSD treatments have been reported in two of these meta-analyses (Kuester at al., 2016; Sloan at al., 2011). It is worth noting that dropout rates varied widely (range $=4 \%-54 \%$ ). The relatively high dropout rates observed in some studies might be related to known difficulties when working with posttraumatic stress patients. These difficulties concern the mistrust that some people manifest after interpersonal violence, as well as the avoidant behaviors and emotional numbing that characterize this disorder (Scott, Sonis, Creamer, \& Dennis, 2006).

In general, the literature shows that much remains to be known regarding which elements of Internet-based PTSD interventions are more beneficial for patients, what types of patients benefit the most, and how and when therapist contact can contribute to treatment gains (Amstadter et al., 2009; Bolton \& Dorstyn, 2015; Kuester et al., 2016: Sloan et al., 2011).

\section{Theoretical framework}

Cognitive-behavioral theories for PTSD guided the development of the SIN-E-STRES program. Although cognitive-behavioral theory comprises a variety of approaches, they all share certain ideas regarding the following aspects: learning, the processing of cognitive and emotional information, the role of the meanings that people attribute to their experiences, and the behaviors that people implement to cope with the aftermath of a traumatic experience. Relevant concepts for this study, their therapeutic implications, and some examples are presented below.

In the cognitive-behavioral framework, some PTSD symptoms are the result of associative fear-learning. In a traumatic situation, a neutral stimulus becomes anxiogenic when paired with a naturally aversive stimulus (Lissek \& van Meurs, 2015). Furthermore, when the conditioned stimulus is paired with another neutral stimulus, the later also becomes aversive (Foa, Steketee, \& Rothbaum, 1989). Some form of conditioned response is present in most people who go through a traumatic experience. For the majority, new experiences allow the conditioned response to be extinguished. In PTSD, the fears persist. In this regard, Mowrer proposed (as cited in Foa et al., 1989) that this persistence is due to sustained anxiety avoidance behaviors that prevent the conditioned stimulus from occurring in the absence of the aversive unconditioned stimulus. These ideas are fundamental for exposure techniques (in vivo or imaginal), which are a core component of cognitive-behavioral therapies. 
Additionally, Lang (1979) models emotional imagery as a conceptual structure which contains stimulus and response information embedded in a semantic network. Foa and Kozak (1986) proposed that for a fear network to be dismantled, the memory must be activated, and new cognitive and affective corrective information must be incorporated. In therapy, patients are guided to relive the traumatic experience in their imagination. If the arousal response is activated and sustained long enough the fear reaction decreases (a phenomenon that has been labeled as habituation). Habituation by itself constitutes information that changes the response aspect of a person's fear structure. In addition, clinical observations suggest that exposure to a feared situation also modifies its meaning (Foa \& Kozak, 1986).

In another influential formulation, Ehlers and Clark (2008) argued that PTSD is the result of processing the traumatic experience in a way that leads to a sense of current threat. Excessive negative appraisals of the trauma and/or its sequelae contribute to the maintenance of the sense of threat. Problematic behavioral and cognitive strategies prevent the modification of the negative appraisals and memories of the trauma. Furthermore, disturbances in the integration of the trauma episode in autobiographical memory also distort people's perceptions of security. Consequently, therapy interventions based on this understanding encourage patients to reevaluate and modify their erroneous appraisals as well as their dysfunctional coping strategies. It is also important for this therapeutic approach to help patients work through and integrate their recollections of the traumatic event in the context of their lives.

The construction of the SIN-E-STRES program also considered the role of self-efficacy in people's recovery from traumatic experiences, as formulated within the framework of social cognitive theory. Benight and Bandura (2004) define self-efficacy as the perceived capability to manage one's personal functioning and the environmental demands of the aftermath of a traumatic experience. For these authors, a threat results as the assessment of the perceived coping capabilities of a person and the potential pernicious aspects of the environment. Coping efficacy beliefs influence how potential threats are cognitively processed and how well individuals manage demanding situations. Efficacy beliefs contribute to reducing stress by enabling individuals to mobilize and sustain coping efforts. Benight and Bandura (2004) report consistent findings in multiple studies regarding the enabling and protective role of self-efficacy beliefs when managing the impact of traumatic situations. Self-efficacy can be fostered by interventions such as guided enactive attainments, monitoring and reinforcement (feedback from self-monitoring or record keeping), social modeling of effective coping strategies, and persuasive influence that promotes reappraisals of traumatic experiences and coping capabilities (Benight \& Bandura, 2004; McAlister, Perry, \& Parcel, 2008; WHO, 2012).

\section{Methods}

\section{Study design}

This is a descriptive study set out to explore the feasibility and acceptability of SIN-E-STRES, a new Internet-based intervention for patients with PTSD. Quantitative and qualitative data were collected and analyzed to achieve the study's objectives.

This study explores feasibility in terms of patients' interest in joining the program, the reported connectivity and use of the website components, and adherence to the monitoring component. Acceptability (Kazdin, 1980) is evaluated upon the basis of the satisfaction expressed by the participants, their opinions regarding the program's usefulness, and their assessment of positive and negative aspects of the intervention. 
Like many cognitive-behavioral therapies, SIN-ESTRES included psychoeducational information about PTSD symptoms and the rationale for the exposure technique used in the main treatment. This type of psychoeducation is expected to contribute to the improvement of therapy compliance and increase the likelihood that patients stay in treatment long enough for benefits to be achieved (Gray et al., 2004).
PTSD patients were invited to use SIN-E-STRES in addition to their regular treatment. Patients who refused to participate in the study were asked to express the reasons for their decision. Recruited participants had access to the program for two months before being asked to complete an acceptability questionnaire.

\section{Setting}

The WH is part of the Asociación Chilena de Seguridad (ACHS, Chilean Association of Security), a nonprofit organization that provides work-related insurance and healthcare.

In the WH, patients with PTSD enter a three-month treatment regimen which includes biweekly psychiatric sessions for pharmacological treatment; a psychoeducation workshop about the symptoms of PTSD, the characteristics of treatment, and recommendations of healthy coping strategies; trauma-focused cognitive-behavioral psychotherapy (six sessions); and, in some cases, therapist-assisted in vivo exposure. Psychotherapy regularly includes imaginal exposure, cognitive restructuring, and anxiety management. This treatment model is oriented by well established, evidence-based recommendations for this disorder (APA, 2017).

\section{Intervention}

SIN-E-STRES is an adjunct support and monitoring system for the treatment of PTSD. The program is grounded in theory related to the psychological causes of PTSD and its treatment, as presented previously in this article. For example, like many cognitive-behavioral therapies, SIN-E-STRES included psychoeducational information about PTSD symptoms and the rationale for the exposure technique used in the main treatment. This type of psychoeducation is expected to contribute to the improvement of therapy compliance and increase the likelihood that patients stay in treatment long enough for benefits to be achieved (Gray et al., 2004). To foster self-efficacy, the self-care section of the program website also incorporated guidance for coping with PTSD-related symptoms in everyday life and provided some resources for anxiety management. In the same vein, SIN-E-STRES was designed to help patients monitor their symptoms, to encourage them to follow the recommendations provided in face-to-face treatment, and to reinforce progress toward recovery. Participants had access to SIN-E-STRES for three months. The components of the program include:

(a) Monitoring. Patients received a weekly email with a link to a 6 -item version of the PCL-C questionnaire (PCL-6 [Lang \& Stein, 2005]). After each data entry, the program evaluated the patient's symptoms and automatically selected and sent a feedback message based on a predefined algorithm. Every message was tailored to the reported state of the patient and included recommendations for self-care and treatment adherence. If a participant reported severe impairment (PCL-6 > =24), the SIN-E-STRES administrator received an alert notification and then contacted the patient via email to remind him/her of the possibility of meeting a SIN-E-STRES mental health specialist for an individual chat or phone session. In addition, a notification was sent to the professionals treating the patient at the hospital.

(b) Online or phone counseling. Patients could schedule a 30-minute synchronous session with a psychologist, which was conducted in a private text chatroom on the website or over the phone. A report of the session was included in the patients' medical records and thus made available to the professionals in charge of their treatment at the hospital.

(c) Self-care information. This was a section of the website with text and audiovisual information about PTSD symptoms, its treatment, and self-care and sleep hygiene recommendations. The information in this section was consistent with the 
psychotherapeutic approach of the face-to-face intervention. This section provided complementary information, reinforced psychotherapeutic orientations, and promoted adherence to the regular face-to-face treatment. There was no fixed schedule for browsing the content: patients could access this area at their convenience and as often as they wanted.

(d) Emergency. This section provided emergency information on what to do and who to contact in a crisis.

SIN-E-STRES components and flow of information are illustrated in Figure 1.

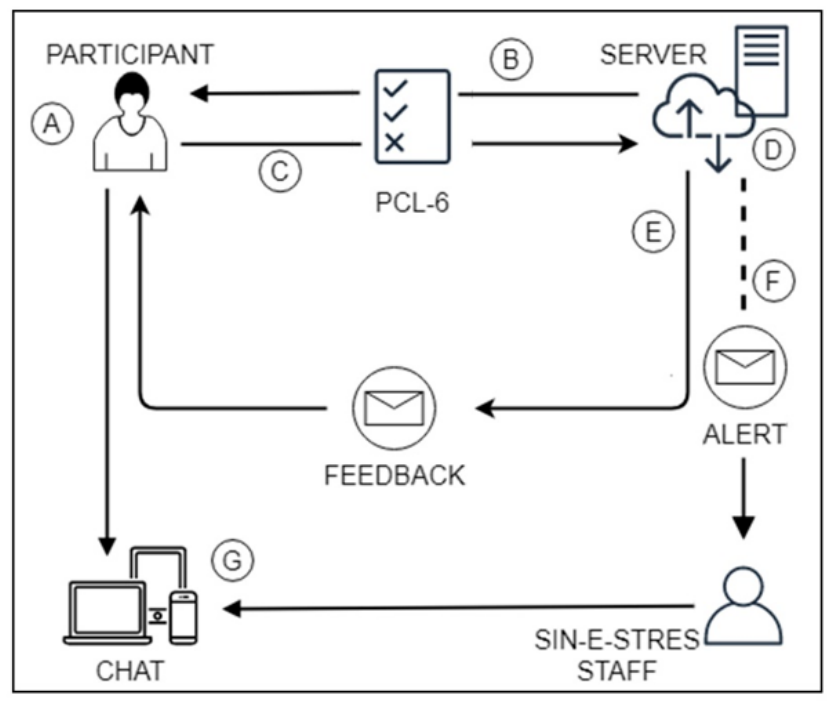

A: Participant is registered in SIN-E-STRES website. Participant has access to: self-care, contact and emergency information, counseling scheduling interface and chat room.

B. Server sends weekly e-mail with a link to the symptom questionnaire (PCL-6). C: Participant submits weekly symptom self-report.

D: Server analyses self-report data and draws tailored feedback message(s) from the database.

$\mathrm{E}$ : Tailored feedback message is sent to participant.

$\mathrm{F}$ : If severe impairment is detected (PCL-6 $>=24)$, an alert message is sent to mental health professionals.

$\mathrm{G}$ : If requested, psychotherapist and participant meet in a secured chat room or in a phone conversation.

Figure 1. SIN-E-STRES components and flow of information

\section{Recruitment}

Candidates suitable for participation in the study were men and women between 18 and 65 years of age, with Internet access and undergoing treatment for PTSD at the WH. Diagnoses of PTSD and of the other disorders considered in the research criteria were based on clinical evaluations by the hospital's psychiatrists.

Exclusion criteria included acute risk of suicide, a history of psychotic symptoms, bipolar disorder, organic brain disorders, any serious disorders related to substance abuse or dependence, a serious medical condition or severe cognitive impairment, trauma from sexual abuse, trauma due to limb amputation or other severe organic damage, insufficient knowledge of the Spanish language, illiteracy, and the refusal or revocation of patient consent.

Patients who me the inclusion criteria were invited to participate in the study at different stages of their regular treatment by their treating mental health professional. Two clinical psychologists recruited the participants, who were asked to attend a recruitment session to become familiar with the intervention, to answer the initial questionnaires, and to provide informed consent.

Out of the 117 patients who agreed to participate, 17 (15\%) had to be excluded due to the inclusion/exclusion criteria, 23 (20\%) could not be reached by phone, 10 (9\%) were discharged before the research team contacted them, and 22 (19\%) did not attend the recruitment session. Thus, the final sample included 45 patients (Figure 2). 
09-2015

\begin{tabular}{|c|c|}
\hline 157 & Patients invited to participate \\
\hline & $\begin{array}{l}23 \text { patients refused to participate } \\
\text { reporting no internet access or not } \\
\text { being internet users } \\
5 \text { refused to participate without } \\
\text { providing reasons and } 12 \text { provided } \\
\text { several different reasons }\end{array}$ \\
\hline 11 & Patients accepted to participate \\
\hline & 23 patients were unreachable \\
\hline 94 & Contacted patients \\
\hline & $\begin{array}{l}10 \text { patients were discharged } \\
\text { before contact } \\
22 \text { did not attend the recruitment } \\
\text { session } \\
17 \text { did not meet research criteria }\end{array}$ \\
\hline 45 & Registered patients \\
\hline & 12 patients did not use the program \\
\hline 33 & Active users \\
\hline
\end{tabular}

03-2016

Figure 2. Recruitment flowchart

\section{Participants characteristics}

Twenty-nine (64\%) of the registered participants ( $N=45)$ were women. The average age of the patients was 38.95 years $(S D=9.03)$. Patients in the study included clerks, salespersons, cashiers, security guards, drivers, and one teacher.

Regarding the type of trauma that triggered the PTSD, 28 patients (62\%) were mugged, 10 (22\%) were involved in a car accident, 3 (7\%) suffered workplace accidents, 3 (7\%) were assaulted in their workplace, and $1(2 \%)$ reported sexual harassment.

The mean PCL-C score at admission to the study was 58.95 (SD $=12.17$ ), while the mean PHQ-9 score was 15.66 (SD = 5.88).

\section{Assessments}

Patients who were invited but refused to participate in the study were asked to express, anonymously and in writing, the reasons for their decision.

At recruitment, patients completed a socio-demographic questionnaire, which included questions about the devices they used to connect to the Internet and how often they checked their emails. At this initial evaluation, patients also provided answers to the PTSD Checklist-Civilian version (PCL-C [Vera-Villarroel, Zych, Celis-Atenas, Córdova-Rubio, \& Buela-Casal, 2011]), and the PHQ-9 depression questionnaire (Baader et al., 2012). These instruments were used to characterize participants according to relevant variables and determining their initial impairment. 
Two months after being enrolled in the program, patients received an acceptability questionnaire by email. This is a self-developed questionnaire that includes Likert scale and other closed-ended questions regarding satisfaction with SIN-E-STRES, perceived usefulness of its components and, the use of mobile phones to interact with the program. The questionnaire also includes two open questions about positive and negative aspects of the program or recommendations to improve it.
The PCL-C is a widely used 17-item self-report measure reflecting the symptoms of PTSD as described in the Diagnostic and Statistical Manual of Mental Disorders (DSM) IV. A cutoff score of 45-50 points in the PCL-C has been suggested for diagnosing PTSD in mental health clinics (National Center for PTSD, 2014). The PCL-C has demonstrated good psychometric properties in different populations, and it has been validated in Chile (Elhai, Gray, Kashdan \& Franklin, 2005; Vera-Villaroel et al, 2011).

The PHQ-9 is a self-report questionnaire that assesses the levels of depression with nine items addressing key symptoms in the past two weeks. Score ranges for categorizing levels of depression on the PHQ-9 are as follows: $0-4=$ minimal, $5-9=$ mild, $10-14=$ moderate, 15-19 = moderately severe, and 20-27 = severe (Kroenke, Spitzer, \& Williams, 2001). The PHQ-9 is a reliable and valid measure of the severity of depressive symptoms and has proven to be a useful self-report instrument for screening and monitoring depression in several countries, including Chile (Baader et al., 2012; Löwe et al., 2004). The study of Baader et al. (2012) found that $10.8 \%$ of the evaluated sample $(n=1367)$ had symptoms corresponding to major depression and $12.4 \%$ reported symptoms indicative of minor depression.

Two months after being enrolled in the program, patients received an acceptability questionnaire by email. This is a self-developed questionnaire that includes Likert scale and other closed-ended questions regarding satisfaction with SIN-E-STRES, perceived usefulness of its components and, the use of mobile phones to interact with the program. The questionnaire also includes two open questions about positive and negative aspects of the program or recommendations to improve it.

Participants who did not use the program were contacted via telephone and interviewed in order to assess their reasons for not using it. These patients continued with their usual treatment but were not contacted again for the purposes of this study.

Data were collected between October 2015 and June 2016. Answers to the items of the acceptability questionnaire as well of data from the other instruments mentioned above are presented in the results section below.

\section{Data analysis}

Frequencies and percentages were obtained for answers to the questions about reasons to refuse to participate or for being excluded of the study, use of smartphones to access the Internet and SIN-E-STRES, use of email, monitoring response rate, reasons for not responding to the monitoring questionnaires, and satisfaction with SIN-E-STRES.

Means and standard deviations were calculated for the number of completed monitoring questionnaires, for the PCL-C, and PHQ-9 scores.

Quantitative analyses were conducted with IBM SPSS and Microsoft Excel.

Answers to open questions about positive and negatives aspects of SIN-E-STRES and recommendations for improving it were analyzed using qualitative content analysis techniques. The answers were incorporated into a qualitative database using QDA Miner Lite software.

Qualitative content analysis seeks to classify text data into categories that represent similar meanings (Hsieh \& Shannon, 2005). For this study, three general categories were created a priori: positives aspects, negatives aspects, and recommendations. Under these three general categories, an inductive content analysis was performed 
on the answers of the participants. Each answer was read, analytic categories were emergently created, and using these categories the text was coded. The next step was to review the categories and make a descriptive summary.

\section{Results}

\section{Patients' interest in joining the program}

Forty (25\%) of the 157 patients invited to use SIN-E-STRES refused to participate (Figure 2). Twenty-three patients (15\%) mentioned that they did not want to join the program because they were not Internet users, 5 (3\%) did not provide any reasons, 5 (3\%) said that they needed to resolve other personal or health problems, $3(2 \%)$ argued that they had no time, and 4 (2\%) mentioned several reasons for not joining the program, including wanting to self-heal, not wanting to remember the traumatic situation, preferring a face-to-face treatment, and living in a different city.

\section{Connectivity and email use}

All participants reported having Internet access and 38 (84\%) were able to use their smartphones to connect to the web. Seven patients (16\%) stated that they never checked their email, 17 (38\%) did so every two or three days, and 21 (46\%) read their messages at least once a day.

Although some patients reported not being frequent Internet or email users, during the recruitment sessions it was noted that they did use social media or mobile applications for their daily communication needs.

Sixteen patients (36\%) reported having accessed the SIN-E-STRES website at least once from their mobile phones. Seventeen patients (38\%) reported having completed the monitoring questionnaires on their phones.

\section{Monitoring response rate}

Seventy-three percent of the registered patients completed at least one of the 14 monitoring assessments over the three-month period. The average number of completed monitoring questionnaires was $4.84(\mathrm{SD}=4.61)$.

Fifty-eight percent of the patients responded to the first monitoring questionnaire, but the response rate declined over time (Figure 3). The overall monitoring response rate was 35\% (218 answers out of 630 questionnaires sent).

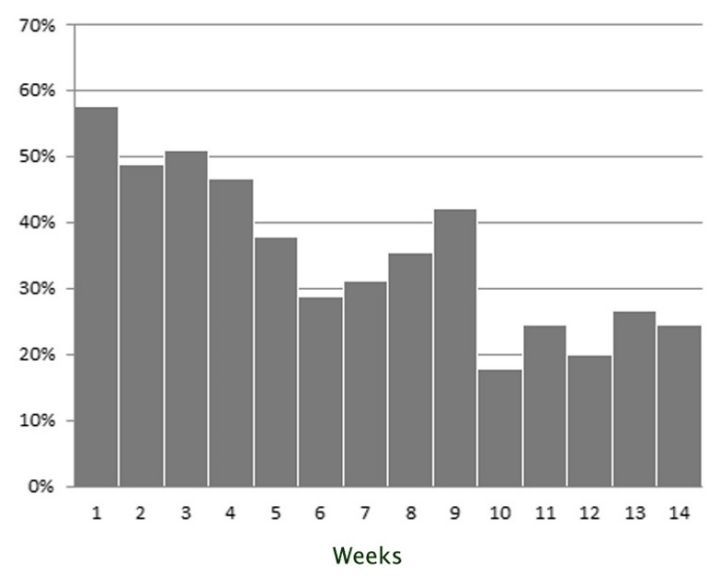

Figure 3. Monitoring response rate by week 
It was possible to contact 10 (83\%) of the 12 patients who did not respond to any of the questionnaires and ask them about their reasons for not answering. Five patients mentioned that they had Internet access problems; 4 mentioned that they rarely checked their email and thus missed the messages with the link to the monitoring assessment; 2 mentioned that they were overwhelmed by the psychological consequences of the traumatic experience; 2 mentioned that in addition to their conditions, they had other problems that required their attention; 2 stated that they were uninterested in the program; and 1 reported that the hyperlinks to the questionnaires did not work properly.

\section{Acceptability}

Thirty (91\%) of the 33 patients who responded to at least one monitoring questionnaire completed the acceptability questionnaire. Overall, these participants were satisfied with SIN-E-STRES (Table 1).

Table 1. SIN-E-STRES: acceptability of and satisfaction

\begin{tabular}{|c|c|c|c|c|c|c|c|c|}
\hline & \multicolumn{2}{|c|}{$\begin{array}{l}\text { Strongly } \\
\text { disagree }\end{array}$} & \multicolumn{2}{|c|}{ Disagree } & \multicolumn{2}{|c|}{ Agree } & \multicolumn{2}{|c|}{$\begin{array}{l}\text { Strongly } \\
\text { agree }\end{array}$} \\
\hline & $F$ & $\%$ & $f$ & $\%$ & $f$ & $\%$ & $f$ & $\%$ \\
\hline $\begin{array}{l}\text { In general, I am satisfied with } \\
\text { SIN-E-STRES. }\end{array}$ & 0 & $0 \%$ & 0 & $0 \%$ & 21 & $70 \%$ & 9 & $30 \%$ \\
\hline $\begin{array}{c}\text { I have learned about beneficial } \\
\text { mental health self-care } \\
\text { behaviors in SIN-E-STRES. }\end{array}$ & 0 & $0 \%$ & 3 & $10 \%$ & 17 & $57 \%$ & 10 & $33 \%$ \\
\hline $\begin{array}{c}\text { Participating in SIN-E-STRES } \\
\text { has allowed me to learn about } \\
\text { PTSD. }\end{array}$ & 0 & $0 \%$ & 3 & $10 \%$ & 16 & $53 \%$ & 11 & $37 \%$ \\
\hline $\begin{array}{l}\text { SIN-E-STRES made me feel } \\
\text { that my health was being taken } \\
\text { care of. }\end{array}$ & 0 & $0 \%$ & 2 & $7 \%$ & 19 & $63 \%$ & 9 & $30 \%$ \\
\hline
\end{tabular}

Note. $f=$ frequency. $\%=$ percentage

Fourteen patients (47\%) agreed with the statement that participating in the SIN-E-STRES program was very beneficial to them; for $11(37 \%)$, participating was mildly beneficial; and for five $(17 \%)$ it was neither beneficial nor harmful.

Participants did not access all the SIN-E-STRES modules available to them. Those who used the resources mostly considered them to be useful or very useful (Table 2). 
Table 2. Usefulness of the program's components

\begin{tabular}{|c|c|c|c|c|c|c|c|c|c|c|}
\hline & \multicolumn{2}{|c|}{$\begin{array}{c}\text { Not } \\
\text { useful }\end{array}$} & \multicolumn{2}{|c|}{$\begin{array}{l}\text { Slightly } \\
\text { useful }\end{array}$} & \multicolumn{2}{|c|}{ Useful } & \multicolumn{2}{|c|}{$\begin{array}{c}\text { Very } \\
\text { useful }\end{array}$} & \multicolumn{2}{|c|}{$\begin{array}{l}\text { I did not } \\
\text { use or } \\
\text { check this } \\
\text { resource }\end{array}$} \\
\hline & $f$ & $\%$ & $f$ & $\%$ & $f$ & $\%$ & $f$ & $\%$ & $f$ & $\%$ \\
\hline $\begin{array}{l}\text { The written information } \\
\text { about stress in the self-care } \\
\text { section. }\end{array}$ & 0 & $0 \%$ & 1 & $3 \%$ & 14 & $47 \%$ & 10 & $33 \%$ & 5 & $17 \%$ \\
\hline $\begin{array}{l}\text { The video with relaxation } \\
\text { exercises in the self-care } \\
\text { section. }\end{array}$ & 0 & $0 \%$ & 1 & $3 \%$ & 9 & $30 \%$ & 14 & $47 \%$ & 6 & $20 \%$ \\
\hline $\begin{array}{l}\text { The monitoring strategy (that } \\
\text { is, receiving and answering } \\
\text { the questionnaire and the } \\
\text { feedback that was sent). }\end{array}$ & 0 & $0 \%$ & 5 & $17 \%$ & 12 & $40 \%$ & 11 & $37 \%$ & 2 & $7 \%$ \\
\hline
\end{tabular}

Note. $f=$ frequency. $\%$ = percentage.

Almost all the active users ( $n=29,88 \%$ ) considered that the number of monitoring questionnaires received was adequate.

Most patients evaluated the feedback messages positively (Table 3). A subgroup of patients $(21 \%-24 \%)$ reported that the feedback messages were not helpful to them.

Table 3. Evaluation of feedback messages

\begin{tabular}{|c|c|c|c|c|c|c|c|c|}
\hline & \multicolumn{2}{|c|}{$\begin{array}{l}\text { Strongly } \\
\text { disagree }\end{array}$} & \multicolumn{2}{|c|}{ Disagree } & \multicolumn{2}{|c|}{ Agree } & \multicolumn{2}{|c|}{$\begin{array}{l}\text { Strongly } \\
\text { agree }\end{array}$} \\
\hline & $f$ & $\%$ & $f$ & $\%$ & $f$ & $\%$ & $f$ & $\%$ \\
\hline $\begin{array}{l}\text { Feedback messages were well suited to } \\
\text { my level of stress. }\end{array}$ & 0 & $0 \%$ & 6 & $21 \%$ & 16 & $55 \%$ & 7 & $24 \%$ \\
\hline Feedback messages were too repetitive. & 2 & $7 \%$ & 7 & $24 \%$ & 14 & $48 \%$ & 6 & $21 \%$ \\
\hline $\begin{array}{l}\text { Feedback messages provided useful } \\
\text { self-care pointers. }\end{array}$ & 0 & $0 \%$ & 6 & $21 \%$ & 19 & $65 \%$ & 4 & $14 \%$ \\
\hline $\begin{array}{l}\text { Feedback messages helped me } \\
\text { remember the themes covered in therapy. }\end{array}$ & 0 & $0 \%$ & 7 & $24 \%$ & 14 & $48 \%$ & 8 & $28 \%$ \\
\hline
\end{tabular}

Note. $f=$ frequency. $\%=$ percentage.

None of the patients used the phone counseling option and only one requested online chat counseling. This person stated that it was easy to book the session, that the counseling was beneficial for her, and that this was a valuable option in the program. 


\section{Qualitative evaluation of the intervention}

Twenty-two patients answered the open question about the positive aspects of the program and 17 patients identified negative aspects or gave recommendations for improving it. In the following paragraphs, a summary of the answers is presented, and some responses are reproduced for illustrative purposes.

Patients highlighted several aspects of the intervention. The most frequent remark $(n=11$ patients) was that the program offered support and that it helped participants overcome their symptoms: "I felt protected"; "There is concern for one's well-being"; "You were always attentive to my needs"; "It helped me manage my fears"; "It was a virtual support in accordance with what I was feeling."

Four patients mentioned that the program helped them to learn about self-care and/or PTSD: "I learned a lot about how to help myself. Excellent"; "The page had in-depth information that helped me a lot." With respect to this aspect, the audiovisual resources were positively assessed ( $n=8)$ : "I really liked the sounds to help me sleep"; "The exercises were very good, useful, and relaxing."

Five patients valued the systematic qualities of the monitoring strategy: "It was very important to me that once a week I had another source of support to face my fears, it was extraordinary"; "It helped me that it is constant, a reminder that I had to visit the web page."

Regarding to the negatively perceived aspects of the intervention, most comments were related to the monitoring strategy $(n=6)$ : "The questions were always the same; after some time, that made me lose motivation to keep answering"; "The follow-up questionnaire sometimes did not reflect my mood, either the questions were not the right ones, or my mood turned out to be very unstable." Regarding the automatic feedback, three participants noted that the messages were "always the same" and "too repetitive."

Two patients mentioned that they were not Internet users; therefore, they found the program difficult to use: "I use the Internet very little, the one time that I tried to connect I received help." Other negative comments were related to difficulties playing the audio files $(n=1)$, repetition of information already provided in the workshop $(n=1)$, and a lack of coordination between the face-to-face treatment and the Internet program $(n=1)$.

Finally, patients made some recommendations. Three patients said that the program would benefit from including some face-to-face contact: "During some of the visits to the hospital, there could have been an opportunity to meet with the people in charge of the program to increase the support we receive or feel a more personal kind of support". Four patients also asked for more "tips", "homework", or more psychoeducational resources. One patient suggested that the monitoring strategy could incorporate an open question "to describe aspects not included in the questionnaire."

\section{Discussion}

Regarding the program's feasibility, it was found that most of the patients invited to the program had internet access and were interested in using SIN-E-STRES. However, the modest response rate to monitoring assessments and patients' reports indicate that, for some people, Internet connectivity is still precarious, and they rarely use the Internet or email.

The level of adherence to the SIN-E-STRES online monitoring component is similar to that of other Internet-based interventions in which moderate-to-low rates have also been 
It could be hypothesized that the emotional burden and cognitive compromise associated with PTSD (APA, 2017) may play a role in treatment adherence (Scott, Sonis, Creamer, \& Dennis, 2006). Also, treatment dropout has been related to patients' efforts to avoid the anxiety that trauma-focused therapy implies (Gray et al., 2004; Lewis et al., 2020). observed (Achilles et al., 2020; Graham et al., 2016). Likewise, non-adherence and dropout rates are issues in conventional PTSD treatment (Draper \& Ghiglieri, 2011: Lewis, Roberts, Gibson, \& Bisson, 2020; Spoont, Sayer, \& Nelson, 2005).

This study did not include methodological strategies to investigate in depth variables related to adherence or dropout. However, researchers contacted ten of the twelve patients who, despite registering for the program, never answered the monitoring questionnaires. In addition to those who referred to connection problems, infrequent use of email, or lack of interest in the SIN-E-STRES program, there were four persons who mentioned their health condition or other unspecified problems as reasons for not using the program.

Related to this last category, it could be hypothesized that the emotional burden and cognitive compromise associated with PTSD (APA, 2017) may play a role in treatment adherence (Scott, Sonis, Creamer, \& Dennis, 2006). Also, treatment dropout has been related to patients' efforts to avoid the anxiety that trauma-focused therapy implies (Gray et al., 2004: Lewis et al., 2020).

Overall, research findings about patient and treatment related predictors of dropout and adherence are still inconsistent, regarding both face-to-face and Internet-based interventions for PTSD (Lewis et al., 2020; Vöhringer et al., 2020). More research about adherence to (and dropout from) treatments is necessary not only in relation to predictors but also to the reasons of patients for abandoning treatment.

To better understand the use of Internet-based interventions, it is also important to consider the technological elements with which users interact (Kelders, Kok, Ossebaard, \& Van Gemert-Pijnen, 2012). Several frameworks for designing and evaluating human-computer interfaces/interactions have been proposed (Gil Urrutia, Brangier, Senderowic, \& Cessat, 2018). From a psychological perspective, there are motivation theories (e.g., self-determination theory [Friederichs et al., 2014; Peters, Calvo, \& Ryan, 2018; Ryan, Rigby, \& Przybylski, 2006 ]), and a theoretical model of engagement with digital health interventions (Yeager \& Benight, 2018; Yeager, Shoji, Luszczynska, \& Benight, 2018) that have guided the design of internet-based treatments. It is beyond the scope of this article to evaluate SIN-E-STRES based on one of these heuristics or theories. However, an iteration of SIN-E-STRES could benefit by considering some of these ideas. For example, as a complement to the monitoring emails, considering that most patients have mobile connectivity and one third of them interacted with the program using their smartphones, it would be interesting to explore safe and simple ways of integrating the SIN-E-STRES program with their everyday electronic communication media (social media or mobile communication applications).

Additionally, the monitoring might be enhanced by updating the questionnaire according to the definition of PTSD included in the DSM-V, which incorporates mood-related diagnostic criteria (APA, 2013). Negative perceptions concerning the usefulness of the feedback messages could affect the credibility of the intervention, a variable that has predicted treatment dropout in some studies (Edmonds et al., 2018; Vöhringer et al., 2020). A broader set of messages and a more complex feedback algorithm could also help make feedback less repetitive and more individualized, improving patients' perception of SIN-E-STRES.

SIN-E-STRES users expressed predominantly positive evaluations of the program in general and of its specific components. The high acceptability of SIN-E-STRES among its users is comparable to that obtained in the evaluation of a similar strategy for patients with depression in Chile in an internet-delivered program (Espinosa et al., 2016). 
It was positive to observe that most patients agreed that the feedback messages helped them remember themes covered in therapy. It is also encouraging that participants valued the psychoeducational resources on the website. Additional complementary psychoeducational content could also improve the SIN-E-STRES program. For instance, since the audiovisual content was positively evaluated, it could be beneficial to offer more information in this format. The fact that patients have convenient access to relevant and quality information may increase adherence to the face-to-face treatment and consequently facilitate improvement (Gray et al., 2004).

It is important to consider that the clinicians in charge of the usual treatment at the WH did not promote or monitor the use of SIN-E-STRES. The main incentive for patients to use SIN-E-STRES was the introductory explanation at the time of recruitment. A synergistic integration between SIN-E-STRES and the main treatment might help attain better overall outcomes.

In conclusion, SIN-E-STRES was well accepted by PTSD patients who used the program as an adjunct Internet-based intervention in addition to conventional care. The program has the potential to improve conventional mental health services by creating a permanent line of communication between provider and patient. The alignment and coherence of SIN-ESTRES with respect to the main treatment, as pointed out by the patients, contributes to reinforcing treatment indications and, consequently, may promote treatment adherence and lead to faster recovery from PTSD.

The program may be especially useful for patients who are frequent Internet and email users. Since young people use the Internet more intensively, it is reasonable to expect a program like SIN-E-STRES to be adopted by new generations of patients, especially if it is integrated with their usual communication media. This study provides preliminary evidence that supports further development of the program and future research on SIN-E-STRES.

\section{Ethics approval}

Approval was obtained from the Ethics Committee of the Hospital del Trabajador (Santiago de Chile, July 15, 2015).

\section{Consent to participate}

Informed consent was obtained from all individual participants included in the study.

\section{Declaration of conflicting interests}

The Authors declare that there is no conflict of interest. 


\section{References}

Abeldaño, R. A., Fernández, A. R., Estario, J. C., Enders, J. E., \& López de Neira, M. J. (2014). Screening de trastornos de estrés postraumático en población afectada por el terremoto chileno de 2010. Cadernos de Saúde Pública, 30(11), 2377-2386. https://doi.org/10.1590/0102-311X00141313

American Psychiatric Association. (2013). Diagnostic and statistical manual of mental disorders (5th ed.). Washington, DC: Author.

American Psychological Association. (2017). Clinical practice guideline for the treatment of posttraumatic stress disorder (PTSD) in Adults. https://www.apa.org/ ptsd-guideline/ptsd.pdf

Amstadter, A., Broman-Fulks, J., Zinzow, H., Ruggiero, K., \& Cercone, J. (2009). Internet based interventions for traumatic stress-related mental health problems: a review and suggestion for future research. Clinical Psychology Review, 29(5), 410-420. http://doi.org/10.1016/j.cpr.2009.04.001

Achilles, M., Anderson, M., Li, S., Subotic-Kerry, M., Parker, B., \& O'Dea, B. (2020). Adherence to e-mental health among youth: Considerations for intervention development and research design. Digital health, 6. https://doi. org/10.1177/2055207620926064

Atwoli, L., Stein, D., Koenen, K., \& McLaughlin, K. (2015). Epidemiology of posttraumatic stress disorder: prevalence, correlates and consequences. Current Opinion in Psychiatry, 28(4), 307-311. https://doi.org/10.1097/YC0.0000000000000167

Baader, T., Molina, J. L., Venezian, S., Rojas, C., Farías, R., Fierro-Freixenet, C., ... Mundt, Ch. (2012). Validación y utilidad de la encuesta PHQ-9 (Patient Health Questionnaire) en el diagnóstico de depresión en pacientes usuarios de atención primaria en Chile. Revista Chilena de Neuro-Psiquiatría, 50(1), 10-22. https://doi. org/10.4067/S0717-92272012000100002

Bauer S., Wolf M., Haug S., \& Kordy H. (2011). The effectiveness of internet chat groups in the relapse prevention after inpatient psychotherapy. Psychotherapy Research, 21(2), 219-26. https://doi.org/10.1080/10503307.2010.547530

Benight, C., \& Bandura, A. (2004). Social cognitive theory of posttraumatic recovery: The role of perceived self-efficacy. Behaviour Research and Therapy, 42(10), 11291148. https://doi.org/10.1016/j.brat.2003.08.008

Benight, C., Ruzek, J., \& Waldrep, E. (2008). Internet interventions for traumatic stress: A review and theoretically based example. Journal of Traumatic Stress, 21(6), 513-520. http://doi.org/10.1002/jts.20371

Bisson, J., Roberts, N., Andrew, M., Cooper, R., \& Lewis, C. (2013). Psychological therapies for chronic post-traumatic stress disorder (PTSD) in adults. The Cochrane Database of Systematic Reviews, 12. https://doi.org/10.1002/14651858. CD003388.pub4

Bolton, A., \& Dorstyn, D. (2015). Telepsychology for posttraumatic stress disorder: a systematic review. Journal of Telemedicine and Telecare, 21(5), 254-67. https:// doi.org/10.1177\%2F1357633X15571996

Castro, A., Larraín, A., Fritsch, R., \& Rojas, G. (2012). Telepsiquiatría: una revisión sistemática cualitativa. Revista Médica de Chile, 140(6), 789-796. https://doi. org/10.4067/S0034-98872012000600015

Draper, C., \& Ghiglieri, M. (2011). Post-traumatic stress disorder. Computer-based stepped care: practical applications to clinical problems. In O'Donohue, W. \& Draper, C. (ed). Stepped care and e-health Practical applications to behavioral disorders. New York, NY: Springer. 
Edmonds, M., Hadjistavropoulos, H. D., Schneider, L. H., Dear, B. F., \& Titov, N. (2018). Who benefits most from therapist-assisted internet-delivered cognitive behaviour therapy in clinical practice? Predictors of symptom change and dropout. Journal of Anxiety Disorders, 54, 24-32. https://doi.org/10.1016/j.janxdis.2018.01.003

Ehlers, A., \& Clark, D. M. (2008). Posttraumatic stress disorder: the development of effective psychological treatments. Nordic Journal of Psychiatry, 62(Suppl 47), 11-18. https://doi.org/10.1080/08039480802315608

Elhai, J. D., Gray, M. J., Kashdan, T. B., \& Franklin, C. L. (2005). Which instruments are most commonly used to assess traumatic event exposure and posttraumatic effects?: a survey of traumatic stress professionals. Journal of Traumatic Stress, 18(5), 541-545. https://doi.org/10.1002/jts.20062

Errázuriz, P., Valdés, C., Vohringer, P., \& Calvo, E. (2015). Financiamiento de la salud mental en Chile: una deuda pendiente. Revista Médica de Chile, 143(9), 11791186. https://doi.org/10.4067/S0034-98872015000900011

Espinosa, H., Carrasco, A., Moessner, M., Cáceres, C., Gloger, S., Rojas, G., ... Krause, M. (2016). Acceptability study of "ASCENSO": an online program for monitoring and supporting patients with depression in Chile. Telemedicine and e-Health, 22(7), 577-583. https://doi.org/10.1089/tmj.2015.0124

Everitt, B. (2006). Medical statistics from A to Z: a guide for clinicians and medical students. Cambridge: Cambridge University Press.

Foa, E. B., \& Kozak, M. J. (1986). Emotional processing of fear: exposure to corrective information. Psychological Bulletin, 99(1), 20-35. http://doi.org/10.1037/00332909.99.1.20

Foa, E. B., Steketee, G., \& Rothbaum, B. O. (1989). Behavioral/cognitive conceptualizations of post-traumatic stress disorder. Behavior Therapy, 20(2), 155-176. https:// doi.org/10.1016/S0005-7894(89)80067-X

Friederichs, S., Oenema, A., Bolman, C., Guyaux , J., van Keulen, H., \& Lechner, L. (2014). I Move: systematic development of a web-based computer tailored physical activity intervention, based on motivational interviewing and self-determination theory. BMC Public Health, 14(212). https://doi.org/doi.org/10.1186/14712458-14-212

Gil Urrutia J.I., Brangier E., Senderowicz V., \& Cessat L. (2018). Beyond "Usability and User Experience", Towards an Integrative Heuristic Inspection: From Accessibility to Persuasiveness in the UX Evaluation. In Ahram T., \& Falcão C. (eds) Advances in Usability and User Experience. AHFE 2017. Advances in Intelligent Systems and Computing, 607. Springer, Cham. https://doi.org/10.1007/978-3-319-60492$\underline{3.44}$

Graham, A., Jacobs, M., Cohn, A., Cha, S., Abroms, L., Papandonatos, G., \& Whittaker, R. (2016). Optimising text messaging to improve adherence to web-based smoking cessation treatment: a randomised control trial protocol. BMJ Open, 6(3), e010687 https://doi.org/10.1136/bmjopen-2015-010687

Gray, M., Elhai, J., \& Frueh, B. (2004). Enhancing patient satisfaction and increasing treatment compliance: patient education as a fundamental component of PTSD. Psychiatric Quarterly, 75(4), 321-332.

Hirai, M., \& Clum, G. (2005). An internet-based self-change program for traumatic event related fear, distress, and maladaptive coping. Journal of Traumatic Stress, 18(6), 631-636. http://doi.org/10.1002/jts.20071

Hsieh, H.-F., \& Shannon, S. E. (2005). Three approaches to qualitative content analysis. Qualitative Health Research, 15(9), 1277-1288. https://doi. org/10.1177/1049732305276687 
Kelders S., Kok R., Ossebaard H., \& Van Gemert-Pijnen J. (2012). Persuasive system design does matter: a systematic review of adherence to web-based interventions. Journal of Medical Internet Research, 14(6), e152. https://doi.org/10.2196/ imir. 2104

Kazdin A. (1980). Acceptability of alternative treatments for deviant child behavior. Journal of Applied Behavior Analysis, 13(2), 259-273. https://doi.org/10.1901/ jaba.1980.13-259

Klein, B., Mitchell, J., Gilson, K., Shandley, K., Austin, D., Kiropoulos, L., ... Cannard, G. (2009) A therapist-assisted Internet-based CBT intervention for Posttraumatic Stress Disorder: Preliminary Results, Cognitive Behaviour Therapy, 38(2), 121 131. https://doi.org/10.1080/16506070902803483

Kordy, H., Wolf, M., Aulich, K., Bürgy, M., Hegerl, U., Hüsing. J., ... Backenstrass, M. (2016). Internet-delivered disease management for recurrent depression: a multicenter randomized controlled trial. Psychotherapy and Psychosomatics, 85(2), 91-98. https://doi.org/10.1159/000441951

Kroenke, K., Spitzer, R., \& Williams, J. (2001). The PHQ-9: validity of a brief depression severity measure. Journal of General Internal Medicine, 16(9), 606-613. https:// doi.org/10.1046/j.1525-1497.2001.016009606.x

Kuester, A., Niemeyer, H., \& Knaevelsrud, C. (2016). Internet-based interventions for posttraumatic stress: A meta-analysis of randomized controlled trials. Clinical Psychology Review, 43, 1-16. https://doi.org/10.1016/j.cpr.2015.11.004

Kuester, A., Niemeyer, H., \& Knaevelsrud, C. (2016). Internet-based interventions for posttraumatic stress: a meta-analysis of randomized controlled trials. Clinical Psychology Review, 43, 1-16. https://doi.org/10.1016/j.cpr.2015.11.004

Lang, A., \& Stein, M. (2005). An abbreviated PTSD checklist for use as a screening instrument in primary care. Behaviour Research and Therapy, 43(5), 585-594. https://doi.org/10.1016/j.brat.2004.04.005

Lang, P. J. (1979). A bio-informational theory of emotional imagery. Psychophysiology, 16(6), 495-512. https://doi.org/10.1111/j.1469-8986.1979.tb01511.x

Lange, A., Rietdijk, D., Hudcovicova, M., van de Ven, J., Schrieken, B., \& Emmelkamp, P. (2003). Interapy: a controlled randomized trial of the standardized treatment of posttraumatic stress through the Internet. Journal of Consulting and Clinical Psychology, 71(5), 901-909. https://doi.org/10.1037/0022-006X.71.5.901

Leon, A., Davis, L., \& Kraemer, H. (2011). The role and interpretation of pilot studies in clinical research. Journal of Psychiatric Research, 45(5), 626-629. https://doi. org/10.1016/i.jpsychires.2010.10.008

Lewis, C., Roberts, N. P., Simon, N., Bethell, A., \& Bisson, J. I. (2019). Internet-delivered cognitive behavioural therapy for post-traumatic stress disorder: systematic review and meta-analysis. Acta Psychiatrica Scandinavica, 140(6), 508-521. https:// doi.org/10.1111/acps.13079

Lewis, C., Roberts, N., Gibson, S., \& Bisson, J. (2020). Dropout from psychological therapies for post-traumatic stress disorder (PTSD) in adults: systematic review and meta-analysis, European Journal of Psychotraumatology, 11(1). https://doi.org/10 $.1080 / 20008198.2019 .1709709$

Lissek, S., \& van Meurs, B. (2015). Learning models of PTSD: theoretical accounts and psychobiological evidence. International Journal of Psychophysiology, 98(3 Pt 2), 594-605. https://doi.org/10.1016/j.ijpsycho.2014.11.006

Litz, B., Gray, M., Bryant, R., \& Adler, A. (2002). Early intervention for trauma: current status and future directions. Clinical Psychology Science and Practice, 9(2), 112134. https://doi.org/10.1093/clipsy.9.2.112 
Löwe, B., Kroenke, K., Herzog, W., \& Gräfe, K. (2004). Measuring depression outcome with a brief self-report instrument: sensitivity to change of the Patient Health Questionnaire (PHQ-9). Journal of Affective Disorders, 81(1), 61-66. https://doi. org/10.1016/S0165-0327(03)00198-8

McAlister, A., Perry, C., \& Parcel, G. (2008). How individuals, environments, and health behaviors interact. Social cognitive theory. In Glanz, K., Rimer, B., \& Viswanath, K. (Eds.). Health behavior and health education theory, research, and practice (pp. 169-188). San Francisco, CA: Jossey-Bass.

Mowrer, O.H. (1960). Learning theory and behavior. New York: Wiley.

National Center for PTSD, US. Department of Veterans Affairs. (2014). Using the PTSD checklist for DSM-IV (PCL). Retrieved January 29, 2018 from National Center for PTSD website: https://www.ptsd.va.gov/professional/assessment/adult-sr/ ptsd-checklist.asp

National Institute for Health and Clinical Excellence. (2009). Depression in adults: recognition and management. Clinical guide. Retrieved May 22, 2020 from National Institute for Health Care Excellence website: https://www.nice.org.uk/guidance/ cg90/resources/

Pérez, C., Vicente, B., Zlotnick, C., Kohn, R., Johnson, J., Valdivia, S., \& Rioseco, P. (2009). Estudio epidemiológico de sucesos traumáticos, trastorno de estrés post-traumático y otros trastornos psiquiátricos en una muestra representativa de Chile. Salud Mental, 32(2), 145-153. Retrieved May 31, 2020 from: https:// www.ncbi.nlm.nih.gov/pmc/articles/PMC2990643/

Peters, D., Calvo, R., \& Ryan, R. (2018). Designing for motivation, engagement and wellbeing in digital experience. Frontiers in Psychology, 9, 797. https://doi. org/10.3389/fpsyg.2018.00797

Richards, D., Timulak, L., Doherty, G., Sharry, J., Colla, A., Joyce, C., \& Hayes, C. (2014). Internet-delivered treatment: its potential as a low-intensity community intervention for adults with symptoms of depression: protocol for a randomized controlled trial. BMC Psychiatry (14), 147. https://doi.org/doi.org/10.1186/1471244X-14-147

Ryan, R., Rigby, C., \& Przybylski, A. (2006). The motivational pull of video games: a self-determination theory approach. Motivation \& Emotion, 30(4), 344-360. https://doi.org/10.1007/s11031-006-9051-8

Scott, C., Sonis, J., Creamer, M., \& Dennis, M. (2006). Maximizing follow-up in longitudinal studies of traumatized populations. Journal of Traumatic Stress, 19(6), 757769. https://doi.org/10.1002/jts.20186

Sloan, D., Gallagher, M., Feinstein, B., Lee, D., \& Pruneaue G. (2011). Efficacy of telehealth treatments for posttraumatic stress-related symptoms: a meta-analysis. Cognitive Behaviour Therapy, 40(2), 111-125. https://doi.org/10.1080/16506073 .2010 .550058

Spoont, M., Sayer, N., \& Nelson, D. (2005). PTSD and treatment adherence: the role of health beliefs. Journal of Nervous \& Mental Disease, 193(8), 515-522. https://doi. org/10.1097/01.nmd.0000172474.86877.2b

Subsecretaría de Telecomunicaciones, Gobierno de Chile. (2016). Séptima encuesta de acceso, usos y usuarios de Internet. Retrieved January 29, 2018 from SUBTEL website: http://www.subtel.gob.cl/wp-content/uploads/2015/04/Informe-VII-Encuesta-de-Acceso-Usos-y-Usuarios-de-Internet VF.pdf

Vera-Villarroel, P., Zych, I., Celis-Atenas, K., Córdova-Rubio, N., \& Buela-Casal, G. (2011) Chilean validation of the posttraumatic stress disorder checklist-civilian version (PCL-C) after the earthquake on February 27, 2010. Psychological Reports, 109(1), 1-12. https://doi.org/10.2466/02.13.15.17.PR0.109.4.47-58 
Vermetten, E., \& Lanius, R. (2012). Biological and clinical framework for posttraumatic stress disorder. In Schlaepfer, T., Nemeroff, C., editors, Neurobiology of Psychiatric Disorders. 3rd ed. Amsterdam: Elsevier B.V.

Vöhringer, M., Knaevelsrud, C., Wagner, B., Slotta, M., Schmidt, A., Stammel, N., \& Böttche, M. (2020). Should I stay or must I go? Predictors of dropout in an internet-based psychotherapy programme for posttraumatic stress disorder in Arabic. European Journal of Psychotraumatology, 11(1), 1706297. https://doi.org/ $10.1080 / 20008198.2019 .1706297$

Wang Z., Wang J., \& Maercker A. (2013). Chinese My Trauma Recovery, A Web-Based Intervention for traumatized persons in two parallel samples: randomized controlled trial. Journal of Medical Internet Research, 15(9), e213. https://doi. org/10.2196/imir.2690

World Health Organization. (2010). Telemedicine: opportunities and developments in member states; report on the 2nd global survey on eHealth 2009. Retrieved January 29, 2018 from WHO website: http://www.who.int/goe/publications/goe telemedicine 2010.pdf

World Health Organization. (2012). Health education: theoretical concepts, effective strategies and core competencies: a foundation document to guide capacity development of health educators. Retrieved January 29, 2018 from WHO website: http://apps.who.int/iris/handle/10665/119953

Yeager, C. M., \& Benight, C. C. (2018). If we build it, will they come? Issues of engagement with digital health interventions for trauma recovery. mHealth, 4(37). https://doi.org/10.21037/mhealth.2018.08.04

Yeager, C. M., Shoji, K., Luszczynska, A., \& Benight, C. C. (2018). Engagement with a trauma recovery Internet intervention explained with the health action process approach (HAPA): longitudinal study. JMIR Mental Health, 5(2), e29. https://doi. org/org/10.2196/mental.9449 